\title{
Efficacy and safety of prophylactic Bakri balloon tamponade after vaginal delivery in women with low-lying placenta: a retrospective cohort study
}

\author{
Hui Dong, Jie Song, Hongyan Cui, Xu Chen \\ Department of Obstetrics, Tianjin Central Hospital of Gynecology Obstetrics, Tianjin, China \\ Contributions: (I) Conception and design: H Dong; (II) Administrative support: H Cui, X Chen; (III) Provision of study materials or patients: H \\ Dong, J Song; (IV) Collection and assembly of data: H Dong, J Song; (V) Data analysis and interpretation: H Dong; (VI) Manuscript writing: All \\ authors; (VII) Final approval of manuscript: All authors. \\ Correspondence to: Hui Dong. Department of Obstetrics, Tianjin Central Hospital of Gynecology Obstetrics, No. 156 Nankai 3rd Road, Tianjin \\ 300100, China. Email: kessen_435@163.com.
}

Background: Low-lying placenta is a special form of placenta previa and a major cause of postpartum hemorrhage (PPH). As an important hemostatic tool, the Bakri balloon is widely used in the prevention and treatment of PPH caused by placenta previa. Few studies have paid attention to the effect of Bakri balloon after vaginal delivery in women with low-lying placenta. The aim of this study is to evaluate the efficacy and safety of prophylactic Bakri balloon tamponade (BBT) after vaginal delivery in women with low-lying placenta based on a retrospective cohort study.

Methods: Singleton pregnant women with low-lying placenta who had vaginal deliveries at our hospital between January 2015 to December 2020 were enrolled. Women who received prophylactic balloon tamponade immediately after vaginal delivery were defined as the BBT group, while women who underwent routine procedures after vaginal delivery except immediate balloon tamponade were defined as the non-BBT group. The maternal clinical characteristics and outcomes of the two groups were collected and analyzed retrospectively.

Results: A total of 118 women with low-lying placenta were included in the study, with 47 in the BBT group and 71 in the non-BBT group. The postpartum bleeding amount was $339.19 \pm 102.94 \mathrm{~mL}$ at 2 hours and $418.11 \pm 90.73 \mathrm{~mL}$ at 24 hours in the BBT group, while in the non-BBT group the postpartum bleeding amount was $421.55 \pm 106.37 \mathrm{~mL}$ at 2 hours and $505.11 \pm 94.51 \mathrm{~mL}$ at 24 hours, with significant differences between the two groups $(\mathrm{P}<0.05)$. However, there were no significant differences in the postpartum length of hospital stay $(\mathrm{P}=0.085)$ and the incidence of puerperal infection $(\mathrm{P}=0.244)$ between the two groups.

Conclusions: Routine use of prophylactic BBT after vaginal delivery can significantly reduce the postpartum bleeding amount in women with low-lying placenta and does not increase the incidence of puerperal infection and the postpartum length of hospital stay.

Keywords: Bakri balloon tamponade (BBT); vaginal delivery; low-lying placenta; hemorrhage; puerperal infection

Submitted Nov 24, 2021. Accepted for publication Jan 11, 2022.

doi: $10.21037 /$ atm-22-68

View this article at: https://dx.doi.org/10.21037/atm-22-68 


\section{Introduction}

Placenta previa refers to when the placenta partially or completely covers the internal os of the cervix, and is one of major causes of postpartum hemorrhage (PPH) (1). As a particular kind of placenta previa, low-lying placenta is defined as the lowest placental edge to the internal cervical os being less than or equal to $20 \mathrm{~mm}$ measured by transvaginal ultrasonography (2). Similar to placenta previa, low-lying placenta is a major risk factor for $\mathrm{PPH}$ and can lead to morbidity and mortality of the mother and neonate (3). Different from placenta previa, which has clear indications for cesarean section, the delivery mode of lowlying placenta is still controversial. The Royal College of Obstetricians and Gynecologists consider that patients with low-lying placenta are more likely to deliver by cesarean section (4). However, the Society of Obstetricians and Gynecologists of Canada (SOGC) believe that vaginal delivery can be considered in an appropriate clinical environment (5).

$\mathrm{PPH}$ caused by low-lying placenta is usually massive and immediate. Pharmacological interventions often fail to control PPH and surgical interventions may be required. In recent years, several mechanical and surgical interventions to control PPH have been reported, including intrauterine gauze packing, uterine compression suture, uterine artery ligation, uterine artery embolization, and hysterectomy, among others (6-10). Among them, Bakri balloon tamponade (BBT) is an effective tool to control PPH induced by lowlying placenta with a high success rate (11).

In our hospital, patients with low-lying placenta were informed of a higher risk of $\mathrm{PPH}$ and the possibility of emergency cesarean section. The delivery mode was determined by the patient's preference. Women who wanted a vaginal delivery were informed to choose whether to use prophylactic BBT after delivery to prevent $\mathrm{PPH}$ prior to labor. Therefore, women were naturally divided into two groups, namely the BBT group and the non-BBT group.

In our present study, the clinical characteristics and outcomes of the two groups were collected and analyzed to explore whether prophylactic BBT after vaginal delivery for low-lying placenta can decrease the incidence of $\mathrm{PPH}$ and increase the rate of puerperal infection. We present the following article in accordance with the STROBE reporting checklist (available at https://atm.amegroups. com/article/view/10.21037/atm-22-68/rc).

\section{Methods}

\section{Patient enrollment}

This was a retrospective cohort study at a single institution. All singleton pregnant women who were diagnosed as having low-lying placenta and had vaginal delivery at our hospital between January 2015 and December 2020 were identified. Among them, cases younger than 18 years old with anemia (hemoglobin $<110 \mathrm{~g} / \mathrm{L}$ ), hypertensive disorder complications, uterine fibroids, and coagulation disorders were excluded. Low-lying placenta was diagnosed when the length from the lowest placental edge to the internal cervical os was between 0 and $20 \mathrm{~mm}$ determined by transvaginal ultrasonography, which was performed by an experienced sonographer after 36 weeks of gestation or within 1 week before delivery. All procedures performed in this study involving human participants were in accordance with the Declaration of Helsinki (as revised in 2013). The study was approved by the Ethics Committee of Tianjin Central Hospital of Gynecology Obstetrics, Tianjin, China (No. 2021KY042). Individual consent for this retrospective analysis was waived.

\section{Interventions}

In both groups, the common postpartum treatment procedures were as follows: after umbilical cord ligation, oxytocin $10 \mathrm{IU}$ was injected intramuscularly, and another $10 \mathrm{IU}$ in a $500-\mathrm{mL}$ saline drip was administered intravenously. After complete separation of the placenta, $250 \mu \mathrm{g}$ of Carboprost tromethamine was injected into the cervix. The vagina and cervix were examined after delivery, and lacerations were sutured immediately to stop bleeding.

In the BBT group, following the spontaneous separation of the placenta, a Bakri balloon was immediately inserted into the lower uterine segment under ultrasonic monitoring. The balloon was filled with $250-400 \mathrm{~mL}$ warm saline according to the capacity of the uterus. Vagina was packed with two tape gauze to prevent the balloon prolapse. After successful balloon placement, balloon catheter draining amount and vaginal bleeding amount were continuously monitored. Due to the dilatation of the internal orifice of the cervix after vaginal delivery, Bakri balloon was easy to prolapse, thus the balloon position was monitored by observing whether the vaginal gauze fell out of the vaginal 


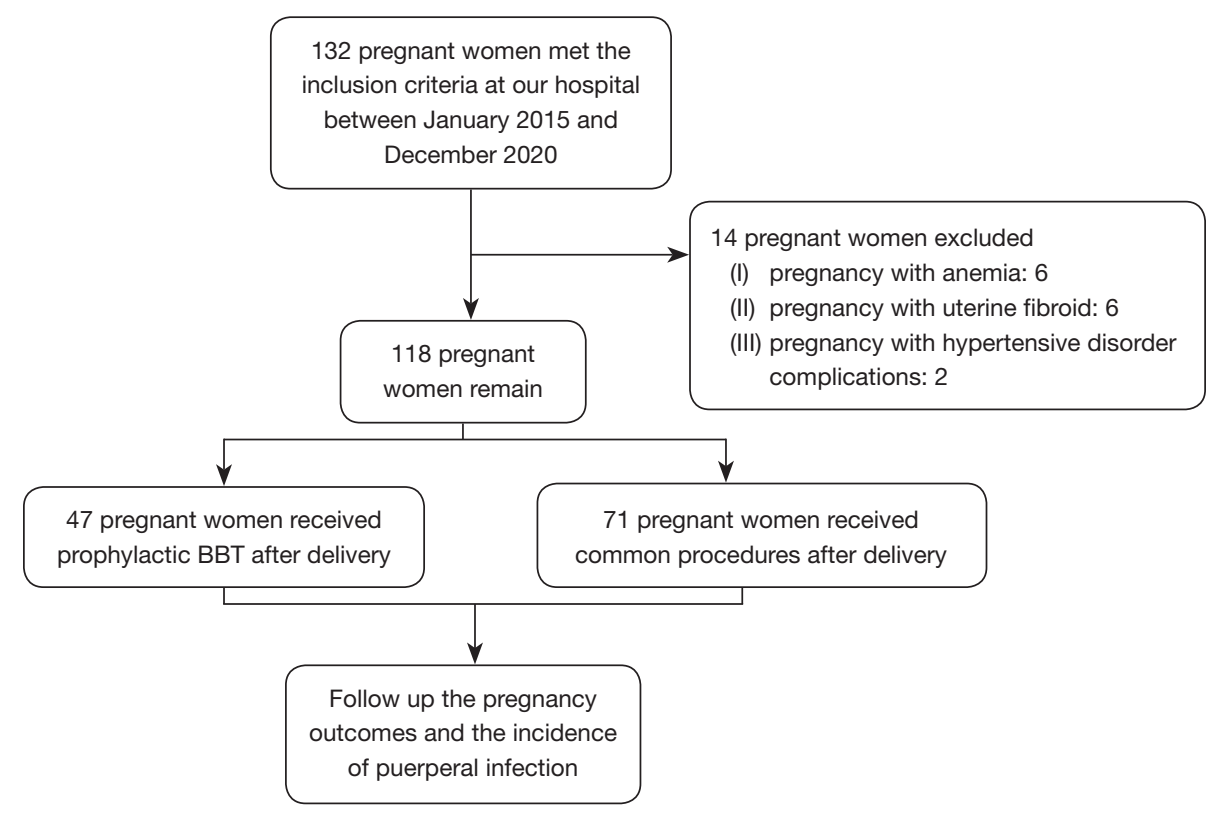

Figure 1 Flow chart of this study. BBT, Bakri balloon tamponade.

orifice. Gauze or balloon prolapse out of the vagina were considered as balloon failure, and the balloon would be reinserted to the correct position under ultrasound monitoring. The Bakri balloon and gauze were removed 24 hours after delivery. In the non-BBT group, there were no additional treatments other than common procedures.

\section{Data collection}

Maternal clinical characteristics and pregnancy outcome data were collected including age, body mass index (BMI), gravida, parity, labor time, placenta location, gestational age at delivery, and placenta-os distance. Primary outcomes were the postpartum bleeding amount within 2 and 24 hours in the BBT and non-BBT groups. Secondary outcomes were the incidence of puerperal infection and the postpartum length of hospital stay in the two groups. Puerperal infection was defined as an axillary temperature above $38{ }^{\circ} \mathrm{C}$ twice a day and a peripheral blood neutrophil count of more than $15 \times 10^{9} / \mathrm{L}$.

\section{Statistical analysis}

Statistical analysis was performed using SPSS 22.0 software (SPSS IBM, NY, USA). Continuous variables were presented as means with standard deviation (SD) and were analyzed with the Student's $t$-test. Categorical variables were presented as number with percentage, and were compared using $\chi^{2}$ tests or Fisher's exact test as appropriate. A P value less than 0.05 was considered statistically significant.

\section{Results}

During the study period, 132 women with low-lying placenta had vaginal deliveries at our hospital. We excluded 6 pregnancies with anemia, 6 with uterine fibroids, and 2 with hypertensive disorder complications, leaving 118 pregnancies for analysis. Among them, there were 47 in the BBT group and 71 in the non-BBT group (Figure 1). All patients were followed up to 24 hours postpartum. Maternal demographic and clinical characteristics are shown in Table 1. There was no significant difference in the maternal age, BMI, gravida, parity, prolonged labor, placenta location, gestational age at delivery, and placenta-os distance between the two groups $(\mathrm{P}>0.10)$. Both groups were comparable in all demographic and clinical characteristics.

The clinical outcomes of the BBT and non-BBT groups are shown in Table 2. The mean postpartum bleeding amount within 2 hours was $339.19 \mathrm{~mL}$ in the BBT group and $421.55 \mathrm{~mL}$ in the non-BBT group $(\mathrm{P}<0.01)$. Twentyfour hours after delivery, the mean bleeding amount was $418.11 \mathrm{~mL}$ in the BBT group and $505.11 \mathrm{~mL}$ in the nonBBT group $(\mathrm{P}=0.027)$. Compared with the non-BBT group, the postpartum bleeding amount was significantly lower in 
Table 1 Maternal demographic and clinical characteristics in pregnancies with low-lying placenta

\begin{tabular}{|c|c|c|c|}
\hline Characteristics & BBT group $(n=47)$ & Non-BBT group $(n=71)$ & $P$ value \\
\hline $\mathrm{BMI}\left(\mathrm{kg} / \mathrm{m}^{2}\right)$, mean $\pm \mathrm{SD}$ & $29.36 \pm 4.57$ & $28.58 \pm 4.83$ & 0.301 \\
\hline Gravida, n [\%] & & & 0.680 \\
\hline 1 & $6[12]$ & $11[15]$ & \\
\hline Parity, $n$ & & & 0.369 \\
\hline Primipara & 11 & 22 & \\
\hline Multipara & 36 & 49 & \\
\hline Prolonged labor (>12 hours), $\mathrm{n}$ & & & 0.257 \\
\hline Placenta location, $\mathrm{n}$ & & & 0.497 \\
\hline Anterior wall & 17 & 27 & \\
\hline Posterior wall & 30 & 44 & \\
\hline Gestational age at delivery (weeks), mean \pm SD & $35.02 \pm 3.38$ & $35.36 \pm 2.78$ & 0.057 \\
\hline Placenta-os distance, $\mathrm{n}$ & & & 0.326 \\
\hline$\leq 10 \mathrm{~mm}$ & 22 & 29 & \\
\hline $10-20 \mathrm{~mm}$ & 25 & 42 & \\
\hline
\end{tabular}

BBT, Bakri balloon tamponade; BMI, body mass index; SD, standard deviation.

Table 2 Clinical outcomes of pregnancies with low-lying placenta

\begin{tabular}{|c|c|c|c|c|}
\hline Characteristics & BBT group $(n=47)$ & Non-BBT group $(\mathrm{n}=71)$ & Odds ratio (95\% Cl) & $P$ value \\
\hline Birth weight $(\mathrm{g})$, mean $\pm \mathrm{SD}$ & $2,910.85 \pm 468.32$ & $2,964.98 \pm 476.73$ & - & 0.674 \\
\hline Blood transfusion, $\mathrm{n}[\%]$ & $5[10]$ & $17[24]$ & $0.326(0.112-0.946)$ & 0.033 \\
\hline Puerperal infection, n [\%] & $6[12]$ & $7[14]$ & $1.338(0.420-4.336)$ & 0.244 \\
\hline $\begin{array}{l}\text { Postpartum length of hospital stay } \\
\text { (days), mean } \pm \text { SD }\end{array}$ & $2.43 \pm 0.71$ & $2.08 \pm 0.63$ & - & 0.085 \\
\hline
\end{tabular}

BBT, Bakri balloon tamponade; BMI, body mass index; SD, standard deviation; Cl, confidence interval. 
the BBT group. In the BBT group, 8 (17\%) women suffered $\mathrm{PPH}$, while in the non-BBT group, $22(31 \%)$ women suffered $\mathrm{PPH}$. The risk of $\mathrm{PPH}$ in the $\mathrm{BBT}$ group was much lower than in the non-BBT group [odds ratio (OR): $0.356,95 \%$ confidence interval $(\mathrm{CI}): 0.142-0.939, \mathrm{P}=0.033$ ] The proportion of patients who required transfusion was significantly lower in the BBT group than in the non-BBT group (OR: 0.326, 95\% CI: 0.112-0.946, $\mathrm{P}=0.033$ ). There were no significant differences in birth weight $(\mathrm{P}=0.674)$, puerperal morbidity $(\mathrm{P}=0.244)$, and postpartum length of hospital stay $(\mathrm{P}=0.085)$ between the two groups.

\section{Discussion}

With the continuous increase of induced abortion, older parturients, multipara, and assisted reproductive technologies, the incidence of placenta previa and lowlying placenta has also increased significantly (1). Although low-lying placenta is associated with maternal and fetalneonatal complications, the incidence of $\mathrm{PPH}$ with lowlying placenta was significantly lower than in women with placenta previa according to a recently published metaanalysis (12). Therefore, low-lying placenta is no longer a specific indication of cesarean section. At the same time, vaginal delivery is chosen by more and more women with low-lying placenta for a variety of reasons, such as fear of surgery, avoidance of abdominal scarring, and cesarean section-related complications. Compared with cesarean section, PPH after vaginal delivery is more difficult to manage because some surgical methods cannot be applied, such as uterine brace sutures and arterial ligation.

Bakri et al. (13) first reported the use of tamponade balloon for the treatment of $\mathrm{PPH}$ due to placenta previa in 1999. Compared to other non-drug treatments of PPH, BBT requires few local resources and does not entail extensive training or complex equipment, and is especially suitable for the treatment of PPH after spontaneous labor (14). Over the past few decades, the utilization of the Bakri balloon has increased significantly, and the effectiveness of BBT for placenta previa has been reported with a high success rate (15). A retrospective cohort study of 163 patients with placenta previa showed that prophylactic use of BBT can significantly decreased perioperative blood loss in patients with major placenta previa; on the contrary, the results showed that BBT cannot effectively reduce the frequency of massive PPH for minor placenta previa (16). For low-lying placenta, a descriptive report analyzed 6 patients with low-lying placenta who underwent elective cesarean section, found that intraoperative BBT placement could reduce the incidence of PPH (17). However, due to the disadvantages of the above studies with a small sample size and lack of control, the conclusion may be biased. Moreover, few reports have investigated whether the prophylactic use of BBT after vaginal delivery in women with low-lying placenta decreases postpartum bleeding and its safety. Therefore, we established a retrospective cohort study to attempt to explore the above questions.

In our retrospective cohort, no significant difference was found in the demographic and clinical characteristics between the BBT group and the non-BBT group. Therefore, the two groups were comparable. By comparing the 2- and 24-hour postpartum bleeding amount between the two groups, we found that the prophylactic use of BBT immediately after delivery can significantly reduce postpartum bleeding, the incidence of $\mathrm{PPH}$, and the blood transfusion rate. Since BBT was performed immediately after delivery, compared with the non-BBT group, the exposure time of the uterus wall was reduced and the uterine cavity pressure was increased, ultimately leading to a significant reduction in uterine bleeding.

Compared to BBT, uterine gauze packing is a more traditional method for preventing and controlling hemorrhage associated with placenta previa and low-lying placenta. But it is not routinely recommended because of the potential possibility of intrauterine infection and concealing ongoing hemorrhage (18). In addition, due to the difficulty of tamping after vaginal delivery, uterine gauze packing was rarely used for the treatment of $\mathrm{PPH}$ caused by placenta previa.

Fever and postpartum infection are the main complications of BBT (19). In order to evaluate the safety of the balloon application, we calculated the incidence of puerperal infection and the length of postpartum hospitalization in the two groups. Our study shows that BBT does not increase the probability of postpartum infection and the length of hospital stay.

There were some limitations in our study, including its retrospective cohort design, small sample size, and singlecenter analysis. Large multicenter prospective cohort studies or randomized controlled trials are needed for further validation.

In conclusion, the routine prophylactic use of BBT for low-lying placenta immediately after vaginal delivery can effectively decrease both postpartum bleeding and the incidence of PPH. BBT does not increase the incidence of puerperal infection and the postpartum length of hospital 
stay. For women with low-lying placenta who want a vaginal delivery, prophylactic BBT could be an effective technique to prevent $\mathrm{PPH}$.

\section{Acknowledgments}

Funding: None.

\section{Footnote}

Reporting Checklist: The authors have completed the STROBE reporting checklist. Available at https://atm. amegroups.com/article/view/10.21037/atm-22-68/rc

Data Sharing Statement: Available at https://atm.amegroups. com/article/view/10.21037/atm-22-68/dss

Conflicts of Interest: All authors have completed the ICMJE uniform disclosure form (available at https://atm. amegroups.com/article/view/10.21037/atm-22-68/coif). The authors have no conflicts of interest to declare.

Ethical Statement: The authors are accountable for all aspects of the work in ensuring that questions related to the accuracy or integrity of any part of the work are appropriately investigated and resolved. All procedures performed in this study involving human participants were in accordance with the Declaration of Helsinki (as revised in 2013). The study was approved by the Ethics Committee of Tianjin Central Hospital of Gynecology Obstetrics, Tianjin, China (No. 2021KY042). Individual consent for this retrospective analysis was waived.

Open Access Statement: This is an Open Access article distributed in accordance with the Creative Commons Attribution-NonCommercial-NoDerivs 4.0 International License (CC BY-NC-ND 4.0), which permits the noncommercial replication and distribution of the article with the strict proviso that no changes or edits are made and the original work is properly cited (including links to both the formal publication through the relevant DOI and the license). See: https://creativecommons.org/licenses/by-nc-nd/4.0/.

\section{References}

1. Gibbins KJ, Einerson BD, Varner MW, et al. Placenta previa and maternal hemorrhagic morbidity. J Matern Fetal Neonatal Med 2018;31:494-9.
2. Reddy UM, Abuhamad AZ, Levine D, et al. Fetal imaging: executive summary of a joint Eunice Kennedy Shriver National Institute of Child Health and Human Development, Society for Maternal-Fetal Medicine, American Institute of Ultrasound in Medicine, American College of Obstetricians and Gynecologists, American College of Radiology, Society for Pediatric Radiology, and Society of Radiologists in Ultrasound Fetal Imaging Workshop. J Ultrasound Med 2014;33:745-57.

3. Lal AK, Hibbard JU. Placenta previa: an outcome-based cohort study in a contemporary obstetric population. Arch Gynecol Obstet 2015;292:299-305.

4. Oyelese Y, Smulian JC. Placenta previa, placenta accreta, and vasa previa. Obstet Gynecol 2006;107:927-41.

5. Oppenheimer L; MATERNAL FETAL MEDICINE COMMITTEE. Diagnosis and management of placenta previa. J Obstet Gynaecol Can 2007;29:261-6.

6. Kellie FJ, Wandabwa JN, Mousa HA, et al. Mechanical and surgical interventions for treating primary postpartum haemorrhage. Cochrane Database Syst Rev 2020;7:CD013663.

7. Uzoma Esike CO. Esike's three-brace suture technique for controlling life-threatening postpartum hemorrhage - A report of two cases. Ann Afr Med 2021;20:141-4.

8. Aoki M, Tokue H, Miyazaki M, et al. Primary postpartum hemorrhage: outcome of uterine artery embolization. $\mathrm{Br} \mathrm{J}$ Radiol 2018;91:20180132.

9. Wang CY, Pan HH, Chang CC, et al. Outcomes of hypogastric artery ligation and transcatheter uterine artery embolization in women with postpartum hemorrhage. Taiwan J Obstet Gynecol 2019;58:72-6.

10. Liu Z, Wang Y, Yan J, et al. Uterine artery embolization versus hysterectomy in the treatment of refractory postpartum hemorrhage: a systematic review and metaanalysis. J Matern Fetal Neonatal Med 2020;33:693-705.

11. Said Ali A, Faraag E, Mohammed M, et al. The safety and effectiveness of Bakri balloon in the management of postpartum hemorrhage: a systematic review. J Matern Fetal Neonatal Med 2021;34:300-7.

12. Fan D, Xia Q, Liu L, et al. The Incidence of Postpartum Hemorrhage in Pregnant Women with Placenta Previa: A Systematic Review and Meta-Analysis. PLoS One 2017;12:e0170194.

13. Bakri YN, Amri A, Abdul Jabbar F. Tamponade-balloon for obstetrical bleeding. Int J Gynaecol Obstet 2001;74:139-42.

14. Dorkham MC, Epee-Bekima MJ, Sylvester HC, et al. Experience of Bakri balloon tamponade at a single tertiary centre: a retrospective case series. J Obstet Gynaecol 
2021;41:854-9.

15. Ozgen G, Aydin GA. Effectiveness of Intrauterine Bakri Balloon $®$ Tamponade for Placenta Previa and Placenta Accreta Spectrum. J Coll Physicians Surg Pak 2020;30:707-12.

16. Arakaki T, Matsuoka R, Takita H, et al. The routine use of prophylactic Bakri balloon tamponade contributes to blood loss control in major placenta previa. Int J Gynaecol Obstet 2021;154:508-14.

17. Patacchiola F, D'Alfonso A, Di Fonso A, et al. Intrauterine balloon tamponade as management of

Cite this article as: Dong H, Song J, Cui H, Chen X. Efficacy and safety of prophylactic Bakri balloon tamponade after vaginal delivery in women with low-lying placenta: a retrospective cohort study. Ann Transl Med 2022;10(2):72. doi: 10.21037/ atm-22-68 postpartum haemorrhage and prevention of haemorrhage related to low-lying placenta. Clin Exp Obstet Gynecol 2012;39:498-9.

18. Bienstock JL, Eke AC, Hueppchen NA. Postpartum Hemorrhage. N Engl J Med 2021;384:1635-45.

19. Suarez S, Conde-Agudelo A, Borovac-Pinheiro A, et al. Uterine balloon tamponade for the treatment of postpartum hemorrhage: a systematic review and metaanalysis. Am J Obstet Gynecol 2020;222:293.e1-293.e52.

(English Language Editor: C. Betlazar-Maseh) 